\title{
A Culturally Immersive Approach to Teaching Cultural Tolerance in
}

\section{a Pandemic}

\author{
Pamela G. Hampton-Garland, Melodee S. Quick, and Catherine O. Ndubuisi
}

Division of Education, Health, and Social Work, University of the District of Columbia

\begin{abstract}
This paper is one approach to teaching graduate students in education to become culturally empathetic. This paper was written when America's racial divide expanded and Black and Brown Americans were killed by police who were not charged, and White American nationalists who want to "Make America Great Again". The pandemic that locked down our nation and stopped business as usual left people isolated and idol thus creating a petri dish for civil unrest to grow. The population of adult educators was immersed in other cultures through critically analyzing ethnographies, memoirs, through the lens of cultural theories. The purpose of this study was to demonstrate that graduate adult education students can develop empathy for populations, they will encounter within their spaces of work that they may feel oppose their access to opportunity. Participants boast about how the narratives reminded them of the common plight amongst populations previously viewed unfavorably. Within these themes, learners acknowledged that the process had transformed how they think about the other.
\end{abstract}

KEYWORDS: Immersion, Cultural Content, Literature, TeacherTraining, Language and Cognition, Teaching Methods

\section{A Culturally Immersive Approach to Teaching Cultural Tolerance in a Pandemic}

The year has showered us with a pandemic that has not ravaged our world since that of the 1918 influenza pandemic which took 50 million lives worldwide. As of this writing there have been more than 2.4 million deaths in 11.5 months from COVID-19 and the numbers are growing. Nevertheless, this is only a part, albeit a critical part, of the crisis faced by our nation. During a war on our health and survival, we also face the possibility of civil unrest including White nationalism, Black Americans senselessly killed by the police, and a narcissistic president whose leadership wreaked havoc on our democracy. As most Americans reside and work at home due to the pandemic, the social engagement that brings people together was nonexistent. Therefore, most Americans who lived and worked in homogenous communities are exposed only to messages that feed our frustrations by attributing them to "the other." With this context in mind, this paper will focus upon one method of teaching cultural difference and tolerance using theory intertwined with memoirs and ethnographies.

This paper will discuss the impact of studying "the self" and "the other" through memoirs and ethnographies undergirded by cultural theories. This paper will employ a discourse of curriculum methodology used to facilitate this culturally immersive experience, discuss the texts used as beacons of light into other ways of knowing and living, in addition to the perspectives of graduate students who enrolled in the course. To provide a voice to the students beyond inference from the professor, the co-authors are former students who took the course and willingly agreed to share their firsthand experiences in this structured culturally immersive curriculum model.

\section{Literature Review}

Research on the topic of teaching immersive cultural experiences through memoir and ethnographic text is limited. However, memoirs and ethnographies are most often used to facilitate learning opportunities for career engagement and others' understanding. Meixner (2009) explored the impact of using teachers' memoirs of their experiences as tools to help facilitate improved close reading for young learners and develop a comprehensive understanding of texts. Others have used memoirs similarly in teacher education. Cross (2020) used memoirs as a tool of engagement to provide preservice teacher education students an opportunity to share their family histories to discover how their personal stories become a tapestry of exploration into cultural difference and similarities, which helped preservice teachers become more conscientious of other cultures by using their written and shared memoirs.

Ethnographies are also tools used to explore and teach empathy, cultural competence and improve clinicians' communication skills. Dominicé Dao (2018) and her team of researchers conducted a review of clinician's ethnographic evaluations that extended back ten years to determine if there was evidence that studying ethnographic evaluations 
improved clinicians' cultural competence. The study revealed that cultural competence gained through evaluating clinical ethnographic evaluations indeed supported institutional, cultural competence by identifying "challenges of caring for diverse patient populations, identifying the training needs of clinicians and gaps in resource provision, and providing hands-on experience with clinical ethnographic interviewing" (Dominicé Dao et al., 2018). The seminal work by Anne Friedman, The Story Catches You and You Fall Down: Tragedy, Ethnography and "Cultural Competence (1997), is examined in Taylor's (2003) article that captures the critical role this book has played in the training of medical doctors. Friedman's (1997) work shed a glaring light upon the missed signals, understandings, mores, and values across cultural lines. Through this tragic ethnography, the medical community learned how wrong things could go when two cultures continue to miss the semiotics that undergirds meaning. "The meanings that we make set the course for the actions that we take" (Taylor, 2003). The culturally relevant training (CRT) via memoirs and ethnographies are used in some preservice teacher training programs. However, not all preservice teachers receive CRT in any form. Although recognized as an essential aspect of teacher development, many students enrolled in educator preparation programs often complete their study program without being introduced to societal issues produced by race, class, and culture (Hutchison \& McAlister-Shields, 2020). Medical schools typically include cultural relevance training once students become clinicians through various approaches, including analyzing ethnographic works. However, many physicians are insufficiently prepared to meet the needs of an increasingly diverse population (Sorensen et al., 2017).

The events of 2020 have brought cultural relevance to the forefront of the 21 st century in completely unexpected but predictable ways. COVID-19 created a nightmare that brought about changes to how the world operates. Our cultural differences were brought to the front of the line, and the actions that followed were predictable. However, our responses left much to be desired as many people built strict alliances with homogenous society members. Our global world will never be a strict binary of them and us and never was, however when our schools disburse hegemony that controls how we think about the other by banning texts, calling news fake, having leaders throughout the world publicly dismiss cultures that are different we cannot expect our children to understand anything differently. Thus, I contend that it is vital to expose individuals to other cultures to expand perspective and challenge personal beliefs of the other and most often of the unknown and feared. The very concept of "culturally relevant training" denotes a practitioner learning a skill to use in the future rather than experiencing the other through culturally immersive engagement. Cultural immersive engagement connotes the idea of jumping in and becoming part of a culture. This subtle but critical distinction changes the narrative of a tool to use when one believes it is necessary to reflect on an experience that alters a particular situation's response. According to Chief Learning Officer contributor, Amy Miranda-Wolff cultural immersion via experiential learning is one of the best forms of adult learning precisely because of its emphasis on exposure and application (2020). Cultural immersion is meant to achieve cultural awareness through experiential learning by creating learning opportunities and facilitating more profound connection points between people who do not typically interact (2020). However, like most organizations, these immersive options are limited mainly because of the costs associated with travel or time constraints for meaningful engagement beyond the institution. This paper contends that immersive cultural engagement can be accomplished in classrooms with intentional instructional design methodologies that involve reading meaningful texts and authoring in-depth papers at the highest Bloom's Taxonomy levels.

Culture, Context, and Critical Andragogy is the graduate course that provides the foundation for this Culturally Immersive Engagement through Critical Analysis of Memoirs and Ethnographies using culturally relevant theories. This course is to assist learners with achieving three primary outcomes:

- Learners will demonstrate an understanding of the historical, political, economic, and social contexts that lead to cultural divergence in urban, suburban, and rural settings.

- Learners will demonstrate their ability to critically analyze complex texts about similar and dissimilar populations and construct new codes of meaning for the other while developing the professional dispositions needed to value others' contributions.

- $\quad$ Learners will begin to develop empathy and respect toward cultural differences among local, national, and global citizens who are systemically underserved.

This curriculum approach adds to the body of cultural relevance in education by focusing on increasing cultural immersion through critically analyzing memoirs and ethnographies using two insightful approaches (1) through the lens of the author and (2) through a theoretical lens. In this course, learners read three (3) texts, usually a combination of memoir, ethnographies, based in the United States and one international country. The process of choosing text includes seeking works that depict adults' lived experiences that learners are likely to encounter within their work environments, works that explore historical relevance to those lived experiences, and works that embody the voice of the population studied.

\section{Implementing the Culturally Immersive Experience}

In this section, I will explain how I set up the structure for the culturally immersive experience. Section one will elaborate on how and why I have chosen the texts used in this course. In section two, I will describe how I introduce and begin initial phase of reading and critically analyzing the texts. Section three will discuss the rationale for the scaffolding and layering of cultural theories and constructs. Finally, section four will focus 
on the final approach I use to shift the learners' understanding from the authors to all text's theoretical underpinnings using qualitative comparative analysis approach. This approach requires learners to examine the three critical analyses they have completed in conjunction with three cultural theories of their choosing that were explored within the course textbook to be used to determine which logical conclusions the narratives support. These processes are analyzed, modified, and refined based upon learner input, outcomes, and andragogical practice each academic year.

\section{Choosing the Books}

For the past three years of teaching this course, I have been consistent in my approach to selecting texts for learners. The approach includes using memoirs and ethnographies that illuminate cultural experiences that are examined and discussed from within the culture or as part of the culture. The process of choosing text includes seeking works that depict adults' lived experiences that learners are likely to encounter within their work environments, works that explore historical relevance to those lived experiences, and works that embody the voice of the population studied. All texts must provide cultural, historical, political, and actual understandings of the populations by those who are members of the group or those who have completed ethnographies that involved living and becoming a member of the group for an extended period either as anthropologists, pure ethnographers or members within the group who have firsthand experience with the society.

The textbook used comprehensively explores theories of cultures through chapter exercises, assignments, and relevance in addition to the three books. The memoirs selected were I am Malala: The Girl Who Stood Up for Education and Was Shot By the Taliban by Malala Yousafzai (2015): Hillbilly Elegy: A Memoir of a Culture and Family in Crisis by J. D. Vance (2018): Code of the Street: Decency, Violence, and the Moral Life of the Inner City by Elijah Anderson (2000): Evicted: Poverty and Profit in the American City by Mathew Desmond (2016): Nigeria: What Everyone Needs to Know $®$ by John Campbell and Mathew Page (2018): Stories of Civil War in El Salvador: A Battle over Memory by Erik K. Ching (2016), and finally the textbook Cultural Studies: Theory and Practice 5th edition by Chris Barker and Emma A. Jane (2016). The authors of the ethnographies and memoirs use textually detailed descriptions of the populations and communities' lived experiences. Choosing text that illuminates lived experiences with observable and experiential data from the voice of those who lived and interpreted the experience is most important for cultural understanding.

\section{Process}

Three weeks before the start of the semester, students are granted access to the syllabus. They are asked to read the class specifications, and to complete the assignment for the first day of class. The assignment requires the student to purchase texts and have them available for class on the first day. Students are provided a list of options for locating the books to assist them with 'budget-friendly' options. This assignment is their first graded homework assignment. One cannot overstate the importance of attaching value to this task, as most learners seek to start the semester strong. Thus, making every effort to complete assignments on time. Additionally, it ensures that learners begin the semester prepared.

Once students arrive, we review the course objectives and reach those objectives during the semester. The course's overall objective for the course is to explore the cultural, historical, philosophical, racial, and socioeconomic factors that influence learning in adulthood. Students will acquire specific critical thinking and analysis techniques to inspire cultural sensitivity and empathy toward the "other." Students have read the syllabus and are cognitively aware of the requirements for the course. Therefore, when they arrive at class, we dive into a detailed discussion of the process and purpose of the 3-10page papers and the 20-page final paper.

\section{Culturally Immersive Critical Analysis}

\section{Pre-Reading for the 3 - Books}

The process is presented in a 3-Phase approach with Phase 1 - focus on the author, Phase 2 - how to annotate the text, and Phase 3 - analyzing a text. In phase one, students follow two brief pre-read assignments. The first requires learners to think about why the author would write about the particular topic. The second asks the readers to ponder the authors' purpose and intent to study the audience or write the memoir on this specific group of people. Learners receive brief examples of what each of these outcomes might look like; for example, the first requires learners to critically think about the author's purpose in authoring the book before they read the book and write a statement to explain why they believe this is the authors' purpose. Students are instructed not to read the author's biography or read reviews for the book, but they may read the book's insert and back cover and the title to develop a coherent answer for why the author penned it. The second pre-reading requirement asks readers to opine why the authors wanted to understand, learn, share, or evaluate the homogenous culture. Learners are asked to write both answers on a Post-it note and put them aside until they have finished reading. Both steps prepare the reader to think more deeply about the text before reading and to formulate an idea about the author's purpose. Pondering the authors' purpose is critical because it causes cognitive dissonance for the reader as they undertake the book. Learners are often seeking to affirm their first impressions; and to learn that their initial opinions might not be entirely true, introduces a cultural awareness based on first impressions. Individuals hold a base knowledge of the world and judge the "other" prematurely. Thus, this process exposes learners to their implicit and explicit biases in a safe 
space where they may begin to critically reflect on how and why they have unfounded views toward the unfamiliar group of people. From a cultural relevance perspective, ignorance of the other is often revealed in settings where mindset shifts are unlikely, and this process provides a way to become aware of and address misconceptions without harming others. It may be a way for future adult educators to modify previously held biases and improve their ability to facilitate learning to individuals unlike themselves.

\section{Annotation for Critical Analysis}

In Phase two, students learn how to annotate the books they will read. Students can use any method they choose to annotate their readings. Students are provided a method for annotating texts that may make the process less complicated. Annotating texts for this course is specific to annotating for critical analysis. This method asks learners to use $3 \times 3$ sticky notes, index cards, and multiple colored note cards or writing utensils for different types of notes. They are to label them Theoretical, Definitional, Evidence, and Surprise. As students read, they are asked to write the page number and the annotation on the right colored note and to place it in a folder or notebook for later use. Students are asked to write the following information on each card (a) page number, (b) the first four words at the beginning of the sentence where the annotation will begin, (c) a brief five-word cue that will help them know why they are annotating this information, (d) write a single sentence to capture the essence of the annotation in their own words with clarity so that it may be added to the paper as-is from the Post-it, without returning to the page (e) put a number on the post-it-note to denote where it is in the annotation list, and (f) students are asked to set the note aside. In total, each annotation may take a minute to complete. This method helps students to do less copying, summarizing, and develop better papers that are focused and analytical as they are not referring to the texts where plagiarizing may occur but to notes taken throughout the reading and readily organized. Furthermore, students are instructed to keep the annotations organized by page and ordered from the first to the last annotation in three separate folders or notebooks. By organizing one's notes, learners can structure their papers as they write about each of the four critical areas above.

\section{Critically Analyzing the Texts}

In phase three, students are introduced to J.L. Beyers "Critically Analyzing an Academic Article or Book" (n.d.) as a guide to critically analyzing the texts. This resource provides learners with a comprehensive approach to writing a critical analysis (CA) paper, and it includes a set of questions for students to ponder as they write on how to frame their analysis. The set of questions draws the writer into a structured way of processing what they have read by focusing on three areas of thinking: theoretical, definitional, and evidential. Students are asked to analyze their annotations and group them as answers to one of Beyer's (n.d.) three question types. Beyers (n.d.) guide provides questions that will assist students in choosing one of the three question types while also focusing them on the consistency of the authors' subjectivity on the topic and the author's implicit or explicit bias noted by the language used throughout the book. The guide also provides brief examples of each of the three question areas, i.e., theoretical questions may be analyzed through a specific cultural theory: Foucault's production of power or Gramsci's hegemony, for examples. Definitional questions come from ambiguity within the text; the reader may read something contradictory to an earlier statement or be introduced to an idea without explanation.

An example of this is in JD Vance's Hillbilly Elegy (2016) when he writes, "Obama strikes at the heart of our insecurities" (p. 191). He discusses his Hillbilly community's disenchantment with Obama but does not address his statement's racist undertone. The definitional questions help writers reflect critically on the author's use of language, both spoken and unspoken. Analyzing textual language may unmask the authors' truths. Evidentiary questions ask the writer to determine if the evidence supports what the author is proclaiming. For example, Elijah Anderson's ethnography "Code of the Street" (1999, p. 141) reports that "...for many young girls who have few other perceivable options, motherhood, accidental or otherwise, become a rite of passage to adulthood", this statement is profound. A reader would look for quotations from the study participants to determine if this broad statement about girls in North Philadelphia and other urban low-income communities is consistent or exaggerated. Lastly, students identify or explain inconsistencies throughout the book and author subjectivity based on the pre-reading assumptions, annotations, and writing style, including the language used, what perspective the author uses to tell the story, and what information is underemphasized or missing from the text. Beyer's (n.d.) guide is thoughtfully used to help guide students from summarizing the text and analyzing the text at the highest level of Bloom's Taxonomy (1956).

\section{Cultural Studies: Theory and Practice}

As learners are introduced to critical cultural analysis methodology, they are immersed in the throes of learning cultural theories with practice. Chris Barker and Emma A. Jane's 5th edition of Cultural Studies: Theory and Practice provide a thorough and expansive study of the theories that undergird our understanding of culture. Students are responsible for the entire book, including all chapter exercises, more in-depth thinking exercises (deconstruct this), and group assignments. We have weekly discussions; learners are provided instructor-based insight videos that demystify challenging theories, and learners are encouraged to work with their cohorts to help explore meaning based on the ideas, thoughts, perceptions and, meaning of their collective voices. This required textbook is rich with examples, to include video suggestions, and models of current events, which provokes 
cognitive dissonance while increasing learner's ability to relate to and distinguish the theories and their theorists. As learners begin to write their first CA paper, they are asked to think about the theories they have studied use them to explain and critique the author's work. Students engage with critically reading a text from the author's perception rather than the story, writing critical analysis papers with evidence, rather than summarizing the reading, and studying completely new concepts indeed activate the whole brain.

\section{Final Critical Analysis Paper}

The final paper requires learners to compare the three books by choosing themes that were manifested throughout each of the texts, and to analyze them using three or more cultural theories from the Cultural Studies: Theory and Practice textbook. This assignment shifts the learners from the author's purpose and intent to the narrative that was written. Students are analyzing the information through a theoretical lens such that the final paper is inclusive of all three books and organized in a logical format where each theme explored through the lens of a cultural theory. For example, learners may choose the theories of Kimberle' Crenshaw's theory of Intersectionality, Marx's theory of Capitalism, and Foucault's theory of Social Control, to explore the impact racial, socioeconomic, and power structures of the affected populations written about in Evicted, Hillbilly Elegy, and I am Malala. Students are permitted to use all available resources, including their previous papers, books, annotations, other notes, textbook, or the internet. Students are reminded that the maximum percentage of plagiarism allowed in all papers, including plagiarism of the self or others, must be less than 6 percent.

\section{Research Method}

To assess how the Culturally Immersive Curriculum method impacted the students' cultural awareness, I applied the critical teacher action research (CTAR) method. This method combines the work of Mills (2011), Tripp (1990), and Atewh, Kemmis, and Weeks (1998), and researching the qualitative action research framework informed my teaching. The exploration and data analysis highlighted areas I need to modify when using this method. The setting, participants, data sources, collection method, and analysis processes are defined and described in this section.

\section{Critical Action Research Study}

The CTAR framework includes the following elements: participation, direction, consciousness, and outcomes. These elements transform adult educators' views and beliefs about the other while also teaching them how to analyze perspective critically. The culture and context course environment is online as a result of COVID. The course is designed to develop and create culturally empathetic educators who will look beyond explicit and implicit understandings of other populations to see humans. This study looked at how the course was taught and the cultural maturity of the learners. The study was conducted to improve how the course is taught and increase students' cultural sensitivities and tolerances. Participation means active learning from all those involved in the working context. In this research, the working context is the cultural context course. My role was researcher where the goal is to analyze how the methodology modifications increased learners' cultural efficacy and as a learner instructor, the goal was to learn from this andragogical self-directed and intrinsically motivating process. The students were participants as they implemented the methodology, reflected upon it, collaborated on assignments, analyzed texts, and used theories to put it all together. The CTAR framework requires that the research has direction. This study improves adult educators' ability to facilitate across all cultural lines, improve praxis when developing curricula that speak to learners across the lifespan and cultural span, and seek community partnerships from benefactors who most often will not mirror the learners. The critical concept of CTAR is that consciousness needs to be explored. This research reveals the embedded values each of the participants has concerning aspirations, ideologies, practices, and discourses about culture as a critical issue for practitioners who are not aware of cultural misogyny. Through analyzing the reflective papers, discussions, interviews, and presentations, I sought to compare the students' perceptions from the beginning of the course to those at the end and document the themes that occurred most often per the students' documents. Using CTAR, there is an inherent commitment to developing, changing, and adjusting approaches and teaching methods based upon the analysis outcomes. This framework initiates an action that may improve adult education practices that disadvantage certain groups of students.

\section{Setting and Participants}

This study took place at a small public urban historically Black college and university on the United States' east coast. For four years from 2016-2020, learners pursuing adult education degrees participated in this culture and context course as a requirement for the master's degree during fall and spring semesters. Participants included 25 learners; 2 White female, 2 White males, 1 White ethnic Russian male, 5 Black males, 2 Black ethnic African males, 12 Black females, 3 Black ethnic African females who ranged in age from $24-67$. After each academic session, the course was revised and modified in response to learners' feedback and my observations of areas where improvement was needed.

However, the data presented in this study were collected from the fall 2020 semester, with five online graduate students 2 Black females, 2 Black males, 1 Black African female. This population permitted the implementation of previous modifications and feedback into a course with a small group. The group size was critical to be able to implement the detailed process. Additionally, implementing this modified program during the pandemic and the cultural unrest in the nation and across the world allowed for rich data and provided learners 
with more significant challenges to understand or empathize with the perceived other.

\section{Data Sources and Collection}

Data were collected from open-ended surveys, students' critical analysis papers, and students' written reflections at the end of the semester. Two students also wanted extra experience with research and were asked to participate by reviewing, analyzing, and conducting semi-structured interviews with other students in the course. Students reflected on aspects of the course, including the text, the writing process, the theories of the culture studied, and their overall perceptions of cultural relevance and engagement. Students were asked thirteen openended questions, including two questions regarding taking the class in the online environment because of COVID-19 (see attachment 1: End of Course Questionnaire).

\section{Findings and Discussion}

Using the constant comparison method (Strauss \& Corbin, 1990) permitted me to become fully immersed in the data. Thus, codes were developed for various themes, followed by reading, re-reading, categorizing, and conversing with the student participants. Member checks were conducted with members of the class to ensure trustworthiness. Learners were sent the interview and reflection analysis to review and edit for accuracy and proper representation of their experiences.

This paper was organized with three critical outcomes expressed by learners of the populations studied. The first outcome focused on the author's stated purpose and how the learners' analysis confirmed or challenged the purpose after reading the book. The second outcome looks at how students incorporated cultural theories into their analysis of the text if students gained different understandings of the population's actions. The third and final outcome focused on identifying the precise shifts in students' cultural awareness and empathy upon completing the course.

The learner participants in this critical teacher action research reported that they learned much about the populations studied, including similarities to their identified cultures, faith, generational past, family values, politics on a lesser level, and plight of their shared socioeconomic status. They were more challenged to understand equity issues with groups that were not their own, even if that group had very similar experiences. Learners also expressed great appreciation for understanding how to analyze the intention and purpose by understanding how to use their pre-read ideas as a base for beginning their analysis, and more importantly how to annotate the texts to improve understanding as expressed here by Caprice;

I have had to change my approach to annotating the text in order to gain a clearer understanding of what is being read. Initially, I found myself simply jotting notes in the margins and highlighting important or thoughtful passages as I went through the reading. Because of unfamiliarity at preparing a in-depth critical analysis my approach nor were my notes very clear. It was difficult for me to abstract specific thoughts from to text and even harder to align those thoughts to theories within the required Cultural Studies textbook.

Reluctant to use the suggested annotation approach initially, Caprice did not perform well on her first paper. As she admits here once she changed her approach she was better able to complete the CA papers going forward;

Table 1: Data Sources

\begin{tabular}{|c|c|c|}
\hline Data Sources & Types of Data & Collected by \\
\hline Student Artifacts & $\begin{array}{l}\text { - Videos from Group Reflective Summaries } \\
\text { - Critical Analysis Papers }\end{array}$ & Faculty Researcher \\
\hline Interviews & $\begin{array}{l}\text { - Semi-Structured interviews with four former students who have } \\
\text { taken the course }\end{array}$ & $\begin{array}{l}\text { Faculty researcher } \\
\text { Participants }\end{array}$ \\
\hline Field Notes & $\begin{array}{l}\text { - Observational notes and informal conversations throughout the } \\
\text { process }\end{array}$ & Faculty Researcher \\
\hline Student Reflections & - Student reflections from insights on readings & Participants \\
\hline $\begin{array}{l}\text { Survey: } \\
\text { Appendix } 1\end{array}$ & $\begin{array}{l}\text { Open-ended questions about the learning process and using } \\
\text { memoirs and ethnographies to explore and understand other } \\
\text { cultures }\end{array}$ & Faculty Researcher \\
\hline
\end{tabular}


Not wanting to use index cards or individual sheets (per note), I developed a spreadsheet listing page number(s) and partial quotes with a brief summary. Later, I added a short annotated bibliography [summary or quote/the significance of what is said/ why or why not important to use for analysis] along with attributing it with a theory learned or further discussed within the required text. Using this approach allows for a more distinctive tactic for attacking critical analysis and overall perspective.

Additionally, learners became more knowledgeable about theories of culture, for example, theories of identity, texture, discourse, language, and the cultural politics of language and how to use them within their critical analysis papers. Learners began to see the author's implicit subjectivity that often was unlike their explicit subjectivity; learners recognized shifts in tone, propaganda to promote or deride a group or action that was not used for the other. Learners began to note differences in word usage, tone, and descriptions among the authors' ingroup audience versus the authors' out-group audience.

\section{Critical Inquiry}

One central theme that appeared most often among students' inquiries regarding the initial pre-reading perceptions. Many of the learners were unfamiliar with at least one of the cultures often led them to draw wholly incorrect conclusions about what would be shared within the pages. One student stated:

... before reading one word from any non-fiction narratives, I had my own biases and preconceived notions based on the titles alone. Because of my background and upbringing within the inner-city, I assumed I was most connected to the subject matter presented by of Desmond's (2016) Evicted and least connected to J.D. Vance's (2016) Hillbilly Elegy.

Although most students accurately connected with the books from their culture, when Chinara, a native Nigerian student expressed some concern over the titles' perceived deceit when writing her reflection.

One would think that the book was entirely about the cultural heritage and practices, food, symbols and exotic tourist places to visit in Nigeria from the book's title. But the title appears deceptive and bogus because it did not really treat the issue it sets out to cover. On reading the book, I discovered that it was not even written by Nigerians but rather by two white American men, who are mere observers, that live ostensibly above the people and not even active participants who were in the field collecting data. These men are outsiders to the culture and history of the entity called Nigeria.

The frustration of this student about the betrayal of a title that appeared to focus on highlighting the culture of Nigeria but focused on the government's troubles is one of the cultural lessons gained by students taking the course. Students have often expressed dismay by the lens with which their own cultures are described rather than express opposition to learning about new cultural experiences. Many believe they need to "set the record straight for their classmates and me. When learners focus on correcting how their culture is perceived per the author, a critical dialogue emerges on identity and perspective, the second theme to emerge.

Identity and perspective as explored by Barker and Janes (2016) chapter on Issues of Subjectivity and Identity, where they share Giddens, (1991) concept of identity as "the self as reflexively understood by the person in terms of her or his biography." In this context, Bryan expressed his concerns for Desmond's (2016) use of language to demonstrate whom this book was targeting and whom it was mentioning abstractly.

A more in-depth look at the author's writing reveals to the reader that this is perhaps a thematic choice. Throughout the book, Desmond makes either conscious or unconscious decisions to remind the reader that he is writing for a white audience. The evidence for this claim is nested in the racial adjectives that the author uses or ignores. Whether referring to the landlord Sherrena "a black woman (Desmond, 2016, p. $3)$," the reference to the birth of Ned's son "with a Mexican girl he had met (Desmond, 2016, p. 47)," or when referring to "'a bodega owned by Arabs"” (Desmond, 2016, p. 53)," the author is telling the reader that this character is not white. Desmond's descriptions of the trailer park residents are rarely if ever, prefaced with the word "white." Desmond's deliberate use of segregating adjectives when referring to the tenants who are the subject of this narrative study occurs in the description of tenants, Ned and Pam. The author never explains to the reader that they are both white but references "Pam's two black girls (Desmond, 2016, p. 48)" as an indicator of this fact.

Bryan identifies as a Black American man; as he analyzed the Evicted text, his understanding of language as power, a concept learned in Barker and Jane's (2016) textbook, alerted him to how an author uses his identity to distinguish the cultures. Bryan sees Desmond (2016) as an author who removes himself and those in his identity group from the narrative by identifying anyone's ethnicity and race, unlike himself to the reader. Targeted writing under the guise of research; specifically, ethnographic research awakens students to who and how identity becomes proliferated by intellectuals who use hegemony to establish false or misleading understandings about perceived inferior groups. The targeted writing approach was dominant and pervasive under former president Donald Trump who used Twitter and video to create beliefs about groups he believed were against him. His power and his use of language compelled millions to adopt his espoused ideals without investigation.

Learners' led to the third and final theme, the regulation of cultural identities and social action. Barker and Janes (2016) chapter on Cultural Politics and Cultural Policy under the subheading of Cultural Politics of Difference where the focus for this theme lies in "the constitutive place of language" or the 
way that language is modified to give existence to something new." Per the text, "the assimilation of poststructuralist thinking has led cultural studies to an understanding of politics that is centered on the power of discourse to describe and regulate cultural identities and social action" (Barker and Jane, 2016). As demonstrated by Caprice, a Black American woman born and living in Washington, DC, who took the class and is one of the student participant researchers, articulates how she connected with the population.

From someone whose experienced evictions as a tenant, I never thought about it from the side of the landlord. The author of Evicted shared a perspective that made me rethink my approach to its process, but I also believe the author wants the audience to see his work from an advocacy perception. Desmond shares the lack of information provided, and the biases asserted to the subject of evictions. None of which I have ever thought about-in all my expertise.

Using this methodology exposes learners to a multidimensional approach to analyzing cultures by evaluating theories, language, evidence, and the authors' use of language as propaganda or a tool to persuade the reader to see and agree with the text and thus embody the authors' views about the population discussed. Students recognized this in their analysis; however, most began to articulate the author's freedom of expression and their need to be conscientious consumers and purveyors of information to action rather than passive receivers of bandwagoners, as demonstrated by Jacob, a Black American male, in his critical analysis of Mathew Desmond's (2016) Evicted: Poverty and Profit in the American City.

After reading the book, I modified my perception of the story by empathizing with some of the characters in the book because of the societal issues that played out in the book. The book highlights to me the hegemonic stance of the author, writing from Eurocentric culture that is not so knowledgeable on the familial culture of the Black people that thrive on communal rather than individualistic living. The author seems judgmental when he insinuates that the Black community is responsible for its housing situation and condition which appears racist.

The past four years have demonstrated just how important it is to know the speaker's intent, especially on January 6, 2021, where former President Donald Trump's devout followers ignored truth and conscience to lead an insurrection at the U.S. Capitol. Students taking this course begin to understand how to critically analyze the speaker and the propaganda that undergirds the message. Roberta's reflection expressed how this course has helped her during this tumultuous health, racial, economic, and politically toxic time.

In the midst the current political state of affairs taking place in America, I may have delved into Vance's Hillbilly Elegy with the most guard-up and preconceived notions. Growing up in a world completely opposite from rural middle state America - my only references are the highly racially charged, anti-taking a knee, politically/racially biased mouth pieces represented on news and social media. Vance's memoir actually shared a piece of his family and culture that allowed the me to see beyond racial hashtags. What I discovered is that the so-called hillbillies of the Appalachians have more in common with the inner-city experience than one would think. Certain segments of the author's viewpoints still indicate a level of racists rhetoric; however, the overall take away is that living in a capitalistic society with little resources, corporations that once sustained you being shut down, education opportunities limited, infrastructure crumbling, drugs and crime surrounding the community would cripple anyone's spirits.

As she and other learners in this course recognized, "the actual constitutions of language and discourse" play a critical role in making meaning. Presidential election year 2020 and its post-impact, many of our fears were realized because of the pandemic, racial unrest, and the divisive leadership responsible for protecting or democracy.

\section{Conclusion}

Culture and context are drivers of perception, propaganda, and understanding, but we often struggle to teach immersive culture to students. Using this process and its revisions have helped increase the agency of adult learners via tools and skills that expose the undercurrent of the messages they hear and the texts they read. Critically analyzing information is vital for adult educators responsible for the training and development of varied audiences, including; human resource agents, program directors, managers, and individuals working with seniors. To understand and teach across the lifespan and cultural lines is an invaluable skill that goes far beyond diversity and inclusion training. Developing meaningful approaches to cultural immersion is difficult in an online space; however, we may have untapped tools at our disposal.

Understanding how to critically decipher language use and its intent is vital. Becoming more competent at using that skill to break down barriers of difference to develop a more inclusive population is priceless. As we have witnessed the abuse of both written and spoken language during the past four years, we must equip our students with the skills to be culturally empathetic.

Cultural immersion is a critical component of pedagogy and andragogy; however, it is often introduced and discussed as something to understand or know, rather than analyze and evaluate. Our personal biases determine how we as educators discuss information; however, this methodology requires the learner to evaluate, critique, take apart, recreate, and struggle with the information presented and then to make informed decisions about the "other" rather than blindly accepting the ideology of the author/speaker.

Cecile Selwyn, the Director of Commonwealth Learning 
Center, described what each brain area is responsible for and how different activities call on distinct parts of the brain (2014). The frontal lobe is where executive functions are activated, like thinking, planning, and problem-solving. The parietal lobe is engaged when perceiving or deciphering something such as spelling. The temporal lobe is responsible for memory, understanding, and language. In contrast, the occipital lobe is for vision.

Additionally, the motor cortex is activated with movement, and the sensory cortex uses one of the senses. Learning is most effective when the whole brain is activated. Thus the composition of this student learning process of reading, writing, composing, producing, reflecting, and analyzing three diverse cultures while studying and applying unfamiliar information moves a learner across the knowledge dimensions of factual, conceptual, procedural, and metacognitive knowledge. This culturally immersive learning level can increase cultural responsiveness unlike anything short of living and working among the "other."

\section{REFERENCES}

1. Anderson, E. (2000). Code of the street: Decency, violence, and the moral life of the inner city. W. W. Norton \& Company.

2. Barker, C., \& Jane, E. A. (2016). Cultural studies: Theory and practice. SAGE.

3. Campbell, J., \& Page, M. T. (2018). Nigeria: What everyone needs to know®. Oxford University Press.

4. Ching, E. (2016). Stories of Civil War in El Salvador: A battle over memory. UNC Press Books.

5. Coles-Ritchie, M. (2013). Reading and analyzing ethnographies through literature circles: A praxis model for encouraging multicultural educators. International Journal of Multicultural Education, 15(1). https://doi. org/10.18251/ijme.v15i1.616

6. Cross, P. T. (2020). Writing Lifestories: A methodology introducing students to multicultural education utilizing creative writing and genealogy. Genealogy, 4(1), 27. https://doi.org/10.3390/genealogy4010027

7. Desmond, M. (2016). Evicted: Poverty and profit in the American city. Broadway Books.

8. Dominicé Dao, M., Inglin, S., Vilpert, S., \& Hudelson, P. (2018). The relevance of clinical ethnography: Reflections on 10 years of a cultural consultation service. BMC Health Services Research, 18(1). https://doi. org/10.1186/s12913-017-2823-x

9. Godbee, \& Novotny. (2013). Asserting the right to belong: Feminist Co-mentoring among graduate student women. Feminist Teacher, 23(3), 177. https://doi.org/10.5406/femteacher.23.3.0177

10. Hutchison, L., \& McAlister-Shields, L. (2020). Culturally responsive teaching: Its application in higher education environments. Education Sciences, 10(5), 124. https://doi.org/10.3390/educsci10050124

11. Litchfield, I., Magill, L., \& Flint, G. (2018). A qualitative study exploring staff attitudes to maintaining hydration in neurosurgery patients. Nursing Open, 5(3), 422-430. https://doi.org/10.1002/nop2.154

12. Meixner, E., Peel, A., Hendrickson, R., Szczeck, L., \& Bousum, K. (2018). Storied lives: Teaching memoir writing through multimodal mentor texts. Journal of Adolescent \& Adult Literacy, 62(5), 495-508. https:// doi.org/10.1002/jaal.935

13. Miranda-Wolff, A. (2020, August 20). Experiential learning through cultural immersion. Chief Learning Officer - CLO Media https://www. chieflearningofficer.com/2019/01/28/experiential-learning-through-cul- tural-immersion/

14. Miranda-Wolff, A. (2020, August 20). Experiential learning through cultural immersion. Chief Learning Officer - CLO Media. https://www. chieflearningofficer.com/2019/01/28/experiential-learning-through-cultural-immersion/

15. Selwyn, C. (2014, October 9). Dyslexia and the brain. Commonwealth Learning Center, Professional Training Institute, \& Commonwealth Learning Online Institute. https://www.commlearn.com/dyslexia-and-thebrain/

16. Sorensen, J., Norredam, M., Dogra, N., Essink-Bot, M., Suurmond, J., \& Krasnik, A. (2017). Enhancing cultural competence in medical education. International Journal of Medical Education, 8, 28-30. https://doi. org/10.5116/ijme.587a.0333

17. Taylor, J. S. (2003). The story catches you and you fall down: Tragedy, ethnography, and "cultural competence". Medical Anthropology Quarterly, 17(2), 159-181. https://doi.org/10.1525/maq.2003.17.2.159

18. Vance, J. D. (2018). Hillbilly elegy: A memoir of a family and culture in crisis. HarperCollins.

19. Yousafzai, M. (2013). I am Malala: The girl who stood up for education and was shot by the Taliban. LittleBrown.

\section{Appendix 1: Survey Questions}

1. Fall semester was quite different from our normal class encounters; what were your greatest concerns with operating in a fully online space?

2. Now that we have completed the course were your concerns realized or mitigated throughout the semester? Provide brief feedback on your response.

3. Specific to Culture and Context Course: The three books that were read (Campbell and Page's Nigeria, Desmond's Evicted, and Vance's Hillbilly Elegy) exposed you to cultures similar and dissimilar to your own, were there any understandings that you garnered from the memoirs and ethnographies that enhanced your understanding of the culture?

4. What impact did writing the critical analysis papers have on understanding the populations that you read about?

5. Your textbook "Cultural Studies: Theories and Practices by Barker and Jane, exposed you to cultural theories that could explain swaths of human behaviors and changes over time; how did this textbook help you to understand the individuals you read about?

6. You read 2 ethnographies and one memoir, do you believe this type of text rather than others (fiction biographies etc.) helped you to feel more connected to the subjects and their culture; if yes, how? If not what do you think would be the best way (via literature) to understand another's culture?

7. How did engaging with the assignments in Barker and Jane's textbook help you get to know your colleagues and yourself through a cultural lens?

8. Do you think this course was a true GRADUATE course with rigor?

9. What did you like about this course as an online course? What did you dislike (other than the amount of writing)? What would you recommend I modify for the next cohort?

10. What did you like about this course as an online course? What did you dislike (other than the amount of writing)? What would you recommend I modify for the next cohort? 
Citation: Pamela G. Hampton-Garland, Melodee S. Quick, and Catherine O. Ndubuisi, "A Culturally Immersive Approach to Teaching Cultural Tolerance in a Pandemic.". American Research Journal of Humanities and Social Sciences, vol 7, no. 1, 2021, pp. 1-10.

Copyright 두 2021 Pamela G. Hampton-Garland, Melodee S. Quick, and Catherine O. Ndubuisi. This is an open access article distributed under the Creative Commons Attribution License, which permits unrestricted use, distribution, and reproduction in any medium, provided the original work is properly cited. 